\title{
Walmir Ayala: a história, a crítica e o ofício das letras ${ }^{1}$
}

\author{
Luís Alberto dos Santos Paz Filho ${ }^{\mathrm{i}}$
}

\begin{abstract}
RESUMO
O presente trabalho tem como objetivo realizar uma apresentação da contribuição intelectual de Walmir Ayala sobre dois aspectos: o primeiro diz respeito à própria produção do autor enquanto escritor; o segundo, mostra a realização de Ayala como crítico e historiador das artes nacionais. Assim, a partir de críticas acadêmicas e jornalísticas, além de consulta em histórias da literatura, busca-se mostrar a importância do autor para o cenário intelectual do país como um embaixador das artes.
\end{abstract}

Palavras-chave: Walmir Ayala; Poesia; Historiografia literária; Crítica literária.

\begin{abstract}
This work aims to present Walmir Ayala's intellectual contribution in two aspects: the first concerns the author's production as a writer; the second shows Ayala's achievement as a critic and historian of the national arts. Thus, based on academic and journalistic criticisms, in addition to consulting literature stories, we intend to show the importance of the author to the country's intellectual scene as an ambassador of the arts.
\end{abstract}

Keywords: Walmir Ayala; Poetry; Literary historiography; Literary criticism.

\footnotetext{
${ }^{i}$ Possui Graduação em Letras (português e suas respectivas literaturas) pela Pontifícia Universidade Católica do Rio Grande do Sul (2017), onde atuou como bolsista de Iniciação Científica no período de 2013 a 2017, tendo participado de pesquisas nas áreas de literatura brasileira autobiográfica e memorialística, e literaturas de língua portuguesa de origens europeia e africana. Possui mestrado em Teoria da Literatura no Programa de Pós-Graduação em Letras da Pontifícia Universidade Católica do Rio Grande do Sul. Atualmente é doutorando em Teoria da Literatura pelo mesmo Programa, sendo bolsista Capes.

ORCID: http://orcid.org/0000-0003-4667-8186 | luis.alberto@acad.pucrs.br
} 
O presente trabalho possui uma dupla missão: por um lado, objetiva realizar um levantamento e uma leitura da presença das produções de Walmir Ayala em materiais de histórias e críticas literárias; em um segundo momento, esta pesquisa possui o intuito de refletir acerca do papel de Ayala enquanto crítico e disseminador das artes, visto que ele foi responsável pela organização de diversas antologias literárias, manuais de artes plásticas, além de traduzir do espanhol diversas obras. A partir desses feitos, podemos considerá-lo um embaixador das letras e outras artes, uma vez que ele contribuiu com a construção de um cânone, ao passo que deu espaço, também, para novas vozes. Mais do que uma provocação sobre o cânone literário e artístico brasileiro, este estudo pretende dar um vislumbre da obra de Walmir Ayala, tanto em seu caráter de escritor literário multifacetado quanto sob a perspectiva de crítico e historiador.

Para entender um pouco da importância de Ayala para o campo das artes brasileiras, pode-se pensar, primeiramente, a partir de alguns estudiosos da história da literatura que não deixaram de mencionar o nome de Walmir em suas obras, justificando, a seguir, as razões que o tornaram relevantes a nível nacional.

Donaldo Schüler, na obra A poesia no Rio Grande do Sul (1987), a partir de concepções de Oswald Spengler a respeito das manifestações vanguardistas europeias, diz que nós, brasileiros, oscilamos entre a utopia e o apocalipse. A partir desses dois elementos, ao refletir acerca da poesia de Ayala, Schüler diz se tratar de uma "esperança eufórica da concretização iminente de sonhos hegemônicos” (SCHÜLER, 1987, p. 307), e destaca a voz lírica de levante social que não aceita a derrota da sociedade consumida pela violência. Ao destacar uma característica otimista frente ao cotidiano, o autor ainda salienta que a poesia de Ayala costuma consolidar imagens de beleza e harmonia, sobretudo ao contemplar a eternidade do momento. A fugacidade das imagens poéticas de Ayala é observada com atenção ao que Schüler chama de humanismo, mais do que religiosidade. Sob essa perspectiva de utopia, há a contemplação de seres que pairam sobre a realidade, não se fixam concretamente, vivendo apenas na possibilidade da representação divina. De acordo com o autor, "o amor saboreia a eternidade no momento que passa e nada procura além dele" (SCHÜLER, 1987, p. 309).

As características brevemente mencionadas por Schüler sinalizam para traços que costumam se destacar nas obras de Ayala: em A pedra iluminada, por exemplo, o caráter humano é constituído de maneira a elaborar sujeitos poéticos que evocam a 
esperança da salvação e da força. Nessa poesia de Ayala não é raro encontrar um discurso positivo engendrado por uma convocação de coletividade. Seu fazer poético encontra base em vozes poéticas de sujeitos líricos que buscam sempre uma reafirmação na vida. Isso porque o discurso poético de Ayala nessa obra está enraizado no desejo do amor: amar, para seus sujeitos líricos, é a única maneira de viver. Publicada em 1976, esta obra realça uma forte tendência que sua poesia nunca abandonaria: a arte só encontra pleno significado quando toca a vida das pessoas. Por isso, o amor é fonte dos questionamentos e das ânsias de seu discurso poético, porque é através do sentimento que se realizam os maiores movimentos e as maiores revoluções sociais.

Marco Lucchesi, por sua vez, em edição de Melhores poemas selecionados de Walmir Ayala, publicada em 2008, escreve, em seu texto de abertura, que "os olhos de Walmir são como os de Argos, compridos, sedentos e abertos para a vida e suas paisagens inacabadas" (LUCCHESI, 2008, p. 9). Ao relatar a necessidade de um estudo aprofundado sobre o conjunto artístico do autor, Lucchesi estabelece um imaginário de Ayala amigo-leitor de Lúcio Cardoso obcecado por algumas mesmas paixões que este tanto literárias quanto da vida. Conectado a essa ideia, ao descrever de maneira mais específica a obra poética de Ayala, Lucchesi diz que não há uma separação clara entre Dionísio e Apolo em sua poesia, mas que esta "se reveste dessa condição ambígua, de oração e morte, do sacrifício cruento à sublimação, do corpo santo ao mais fúlgido erotismo" (LUCCHESI, 2008, p. 11).

Assim como em Cardoso, Ayala constrói grande parte de seu discurso lírico rondando as ideias de sagrado e de profano, em forma de antíteses, sob uma perspectiva da fé cristã. Em Águas como espadas (1983), o poeta volta sua atenção para a constituição do indivíduo. Elaborando um discurso poético atípico dentro de sua vasta produção, nesta obra, Ayala conduz a hermenêutica de sua poesia para um olhar da pequenez humana. O desalento aqui observado encontra refúgio na incerteza da missão de vida do ser humano. Muitos pontos antitéticos são levantados nestes poemas e, em alguns casos, a tranquilidade do eu-lírico aparece como polo oposto à violência e à dinamicidade do mundo, revelando a tendência de que para a completude das ações e da fé é necessária uma farta dose de convicção e delicadeza. Também é preciso salientar que são os sujeitos comuns que elaboram os discursos poéticos em Águas como espadas: trabalhadores de classes mais humildes, pessoas em bares ou em trânsito. Isso 
leva a pensar as relações entre o sujeito do cotidiano com as revoluções da modernidade e a tradição religiosa. Como lidar com a fé em meio às turbulências das novas tecnologias que, cada vez mais, salientam a insignificância do trabalho humano? Através desses questionamentos, a poética de Ayala discursa sobre a eficiência de um encontro consigo próprio: não se pode perder de vista suas próprias convicções.

Ao olhar ainda para outra opinião crítica, temos José Castello que, em sua coluna "Prosa \& Verso", do jornal O Globo, diz, sobre o autor:

poeta da terceira geração do Modernismo, Ayala é, muito mais que isso, um poeta inconfundível, que transforma a poesia em uma fracassada, mas bela, indagação sobre o oculto. Escreve: Assim no escuro te contemplo/ absoluto no que não te mostras. (CASTELLO, 2011, p. 4)

A opinião elogiosa acerca do autor concorda com o jornal A cigarra, no qual em edição de 1966, na sua coluna sobre literatura, diz que "trabalhador infatigável, homem de talento e de sensibilidade, Walmir Ayala vem marcando a sua presença com uma forte atuação em quase todos os caminhos da nossa inteligência” (A CIGARRA... 1966 p. 14). Ao se pensar nessas duas opiniões, o oculto e o absoluto, os caminhos da inteligência encontram espaço na poética de Ayala em outro ponto de extrema relevância: a incansável busca de seus sujeitos líricos por equilíbrio. Na obra Natureza viva (1973), por exemplo, as relações entre sujeito e natureza provocam reflexões sobre a necessidade de se buscar o balanceamento na vida: os espaços, nessa poesia, levam à conscientização da experiência poética como um fenômeno de (re)encontro do humano com o divino, através do natural, do ambiente.

Pode-se perceber a importância que a poesia tem na conjuntura artística de Walmir Ayala. No entanto, essa relevância não se restringe ao campo profisssional. Em sua vida pessoal, a poesia também assume caráter de protagonista. Aos quatro anos de idade, Ayala experencia um forte sofrimento perdendo sua mãe. Este fato, registrado futuramente em seus diários, é uma das forças que o levam à poesia, tanto como escritor quanto como leitor, desde muito cedo, aos nove anos de idade. São, afinal, as relações humanas que pavimentam o brilhante caminho percorrido por Ayala: além de seu pai e sua madrasta, que possibilitam seus primeiros passos como leitor e escritor, amigos como Newton Pacheco e Cecília Meireles fazem parte de sua premiada e aclamada trajetória. Por falar em prêmios, o gaúcho de Porto Alegre colecionou grandes honrarias em sua carreira: em 1956 (apenas um ano após a publicação de seu livro de estreia, 
Face dispersa), já no Rio de Janeiro, ele participa do concurso de poesia Gonçalves Dias no qual, ao utilizar de pseudônimos, acaba vencendo as três primeiras colocações; em 1967, recebe o prêmio de Poesia, concedido pela Fundação do Distrito Federal Protesto Contra a Censura, pelo livro Cantata; Conquista, ainda, em 1972, o primeiro prêmio no Concurso de Literatura Infantil do Instituto Nacional do Livro, pelo livro $A$ Toca da Coruja; Ponte Sobre o Rio Escuro vence o Prêmio Nacional de Ficção do Instituto Nacional do Livro, em 1973; Vence também o Prêmio Bienal Nestlé de Literatura Brasileira, em 1982, pelo livro Cantata; e ainda, no carnaval de 1987, foi homenageado pela Escola de Samba Portela, do Rio de Janeiro, que desfilou com o samba-enredo baseado em seu livro A pomba da paz.

Aclamado pela crítica e tendo seu nome em voga a cada novo lançamento. Assim, a carreira de Ayala foi bem recebida por grandes veículos da imprensa de sua época, além dos críticos de arte, conforme observamos anteriormente. Voltemos, agora, a atenção para o que Ayala tem a dizer sobre si mesmo, sobre seu processo de criação e suas ambições artísticas. Em entrevista dada a Zênia Dirani, do Instituto Estadual do Livro, em 1989, ao ser perguntado sobre o que era a escrita para ele, Walmir Ayala afirma ser "uma vivência cotidiana, um sistema de vida" (AYALA, 1989, p. 4). Ao relatar possuir o hábito da escrita diária, Ayala reforçava o que sua arte fala por si: escrever é uma forma de amar, de lutar e de sobreviver. Dono de um espírito muito livre, segundo suas próprias palavras, tudo o que Ayala mais intentou através de múltiplas vertentes foi encontrar meios de transmitir a paz através da reflexão sobre a vida. Autointitulado como "indisciplinado" nesta mesma entrevista, Ayala diz escrever de forma tumultuosa, sem regramento e por impulso. Ainda sobre este episódio, Ayala diz que "quanto mais brechas a gente tem para se apropriar da beleza da vida, mais concreta será essa aventura" (AYALA, 1989, p. 5) e defende o acesso da arte pelas crianças. Segundo ele, é preciso considerar todo ser humano, independentemente de sua idade, como uma criatura crítica, capaz de ler e de propor interpretações do mundo pela arte. Assim se daria a captação da multiplicidade mágica da existência. Esse posicionamento de Ayala diz muito sobre seu modo de entender a arte: para ele, não há sentido em produzir arte que exclua e oprima, bem como fazer discursos que pretendam segregar ou ainda realizar falas que intentem afastar as pessoas. Seja em seus romances, na sua poesia ou em sua literatura infanto-juvenil, Ayala promove uma arte 
questionadora, reflexiva e afetuosa. $\mathrm{O}$ afeto que, para muitos, pode ser entendido como algo bobo e ingênuo é a principal ferramenta de manifestação do discurso de Ayala: é pelo amor que se vencem os obstáculos. Se, por vezes, o desejo e outros sentimentos podem ser compreendidos como pouco acadêmicos, ou pouco relevantes socialmente, $o$ autor sempre investiu em uma arte na qual eles fossem os protagonistas. Afinal, ao dar tamanha atenção aos sentimentos, Ayala estava dando atenção maior ainda a quem os sentia.

A partir da ideia percebida sobre si mesmo, pode-se pensar a perspectiva de Maria Luiza Ritzel Remédios, que cria uma metáfora para o Walmir-poeta: um artesão das palavras, que busca a transcendência. Segundo ela, o processo de depuração de seus textos revela uma postura perfeccionista que está o tempo todo a se corrigir, refazer e repensar. Conforme a autora,

\begin{abstract}
sua poética vai percorrendo um caminho de contínua redescoberta da realidade profunda das palavras. Insistentemente vai adequando a linguagem à sua história e ao viver, pois, como afirma, "o que fiz foi viver; viver e escrever de forma quase inconsútil. Minha vida foi uma construção". Construir remete a trabalho e elaboração; desse modo, criar é trabalhar, é procura contínua da palavra que se reinventa a cada nova experiência. (REMÉDIOS in.: AYALA, 1989, p. 18)
\end{abstract}

Ao repensar seu texto, Ayala olha para a realidade, fazendo, assim, uma troca de experiências entre sujeito e universo. Olhar para si e para o outro diz respeito a projetar seus desejos no mundo, desejos esses direcionados a Deus. A fé é um dos pontos centrais da vida e da arte de Ayala, conforme mencionado anteriormente e, por isso, acreditar diz muito a respeito do poeta-artesão, que elabora arte como quem realiza uma prece: com otimismo, detalhismo e sutileza. Seu discurso não se faz pela imposição ou pela revolta, mas pela súplica de quem carrega, nas palavras, o peso da vida.

Por se preocupar tanto com a leitura como ética, e, por isso, considerar a literatura um direito a ser universal, o autor dedica sua vida a produzir e a divulgar arte. Sob este viés, Remédios destaca a importância do leitor na obra poética de Ayala. Sobre o mesmo assunto, para observar outra percepção, Antônio Hohlfeldt escreve, em coluna do Correio do Povo, em 1973, intitulada "Esta sondagem cruel e autêntica":

Transformam-se de exercício de leitura individual de cada leitor num encontro elevado ao nível do coletivo, uma vez que sua leitura em voz alta, à maneira dos grandes corais, transforma o texto em algo de uma força 
extraordinária a querer extravasar suas dimensões presas à página de um livro. (HOHLFELDT, 1973, s/p)

Vale reincidir sobre a questão de o reconhecimento à obra de Ayala ter se estendido a diversos polos, conforme apresentado anteriormente, quando foram elencados alguns prêmios e outras honrarias por ele recebidas. Também conforme já mencionado, Walmir Ayala possui uma vasta produção artística, que compreende textos narrativos (conto, novela e romance), poesia, ensaio, escrita diarística e literatura infanto-juvenil, sendo a última uma das áreas nas quais ele recebeu maior distinção. Ainda, além de ser crítico de artes plásticas, literatura e teatro, ele cumpriu missão cultural no Chile e no Paraguai sob incumbência do Ministério das Relações exteriores, e colaborou com diversos jornais, redigindo também programas literários. Essa retomada faz com que nosso interesse se volte, agora, para a crítica acadêmica.

Pode-se dizer, baseado em pesquisas em bancos de dados de artigos, Dissertações de Mestrado e Teses de Doutorado, que a maior parte do material crítico existente sobre Walmir Ayala na atualidade diz respeito à sua produção diarística/memorialística. E sobre este fato, tem chamado a atenção dos pesquisadores seu modo de produção, bem como seus temas, sobretudo no tocante à homossexualidade. Este fato se mostra intrigante, visto que Ayala possui pelo menos quinze livros de poesia inéditos, cerca de cinco romances, pelo menos três livros de contos e dezenas de obras infanto-juvenis. É possível encontrar alguns blogs que comentam brevemente sobre o romance À beira do corpo (1964), mas, de forma geral, a crítica acadêmica tem esquecido de Ayala nas últimas décadas, mesmo tendo ele produzido tanto e sob tantas facetas. Acredita-se, por isso, que se fazem necessários novos olhares acerca deste vasto conjunto artístico e crítico do autor, para além de seus diários.

Destaquemos, então, sobre sua produção diarística, duas percepções, pois embora tratem especificamente do diário de Ayala, seus estudos parecem condizer com uma análise mais ampla do conjunto artístico do autor. Beatriz Damasceno, no texto Anotações, relances, colagens, inventários: os diários inéditos de Walmir Ayala (2015), propõe uma leitura não apenas das obras publicadas, mas também dos seus escritos que ficaram guardados e inacessíveis por muito tempo. Segundo a pesquisadora, a escrita diarística de Ayala é uma exposição das relações entre corpo e alma, nas quais os 
sentimentos, os medos, a fé e a sexualidade participam de um ringue de batalhas por ele registrado. Esses assuntos aparecem sob diversos prismas, em alguns contos e, sobretudo, em romances como em À beira do corpo, Partilha de sombra (1981) e A selva escura (1990).

A passionalidade de Ayala revela ainda, de acordo com Damasceno, a tendência em expor um certo ressentimento sobre as relações humanas, mostrando como são construídas rivalidades e incertezas (DAMASCENO, 2015, p. 259). Nessas escritas diarísticas, o remetente parece mesmo ser Deus, com quem ele não apenas conversa, mas se confessa - essa sensação observada pela autora pode ser notada em grande parte de seus poemas, sobretudo em obras como Face dispersa (1955), Este sorrir, a morte (1957) e Natureza viva (1973). Em uma escrita de súplica e pedido de perdão, o escritor canaliza o que ele entende como essência humana, seja em sua baixeza ou em amostras de caráter benevolente. A condição homossexual surge em um oposto de atrito à religião católica à qual ele é devotado: partindo de experiências e percepções pessoais, Ayala realiza um ensaio de como é viver sob este signo. É válido ainda destacar que o autor dá espaço para reflexões sobre o ato de escrever, permitindo-se divagar a respeito, por exemplo, da construção de seu romance mais notório: À beira do corpo. Em última análise, a escrita de diários, para Ayala, é um ato de rebeldia e purgação.

Sob outra perspectiva, ainda que não tão distante da já citada, Daniel da Silva Moreira, no artigo A fundação de uma escrita autobiográfica dissidente (2018), dá maior importância para a escrita sobre a sexualidade, e assegura que para Ayala o diário é antes de tudo e também um tratado coerente sobre sua trajetória intelectual. Assim, não há um comprometimento em realizar um estudo ou uma concepção geral sobre a identidade gay, mas antes registrar revelações da condição individual de Walmir enquanto sujeito homem homossexual. Usemos como exemplo uma citação do próprio autor, em entrada no diário datada de $1^{\circ}$ de março de 1956 :

Sei, desde hoje, que nasci com a máscara inexpugnável de um animal préhistórico ou de um pássaro empalhado, desses que as populações se apressam em eliminar, e guardam seu espectro para não perder de vista a ameaça das exceções de que são vítimas. (AYALA, 1962, p. 9)

Assim, o autor trata da questão abertamente sem esconder-se em "máscaras" (para utilizar uma expressão de Ayala). E este assunto se mostra tão importante para o 
autor porque o amor é uma de suas obsessões. É o que o autor busca em tudo o que produz: uma forma de encontrar o sujeito sublimado, a essência "real" do sentimento.

Ao se pensar no segundo ponto de interesse deste estudo, temos a inversão de papéis: como é o autor assumindo a postura de crítico e historiador? Conforme dito anteriormente, Walmir Ayala preocupava-se em disseminar nomes de poetas emergentes, figuras que não alcançavam espaço por falta de financiamento e oportunidade. Através de uma carta, Walmir Ayala convida Hilda Hilst a produzir uma versão brasileira de "Cartas a um jovem poeta" (de Rainer Maria Rilke). Acredita-se que foi o jovem Caio Fernando de Abreu, aos 18 anos, cursando Letras na UFRGS, em correspondência a Ayala, que tenha sugerido a ideia. Alan Silvio Ribeiro Carneiro, da Unicamp, no trabalho intitulado Uma carta de Hilda Hilst para um jovem poeta brasileiro (2010), conta esta história. A seguir, um excerto da carta enviada por Ayala para Hilst:

\begin{abstract}
Vamos por ordem: o teu problema editorial é grave, cada vez é mais difícil publicar poesia. As editoras menores estão falindo. As grandes não querem nem ouvir falar em poesia. Tenho a GRD em vista, quem sabe. Tu me mandarias teus originais. Eu me empenharia. Antes disso e com maior urgência eu te peço uma CARTA A UM JOVEM POETA BRASILEIRO, é para um livro que estou organizando. Quase todos os nomes importantes da poesia brasileira, em várias gerações contemporâneas - as estão lá. É uma carta que te defina, que te explique para um jovem que chega e quer saber o que deve fazer para ser poeta. Sinto que está num momento maravilhoso para firmar um documento espiritual da maior importância. Tu, tão jovem e tão bonita estás apta à grande luta com o anjo, transmite isso. Espero esta com urgência, pois o livro está quase pronto. E que não seja pequena, deixa a pena correr, deixa o teu coração fluir como fluiu nesta última carta que me escreveste. E vamos pensar na edição do teu livro, coisa que me interessa muitíssimo. Walmir. (AYALA, 1967, [Carta] jun. 1967 (c), Rio de Janeiro [para] Hilda Hilst, Campinas. (Cedae)
\end{abstract}

A intenção de Ayala em disseminar as artes e novos talentos é evidente nesta e em outras cartas trocadas com amigas e amigos. Assim, para considerar seu papel de crítico e historiador das artes brasileiras, pode-se citar, para além deste projeto, algumas obras produzidas e/ou organizadas por Walmir Ayala que também merecem menção: $A$ Novíssima poesia brasileira (1962); Ou isto ou aquilo (em parceria com Cecília Meireles e Beatriz Bermal) - poemas infantis (1964); Notícias do Paraná: sobre arte paranaense (1965); Antologia dos poetas brasileiros: fase modernista (em parceria com Manuel Bandeira) (1967); A criação plástica em questão (1970); Artistas 
brasileiros: acervo do Grupo Sul América de Seguros (1975); O Brasil por seus artistas (1982); Dicionário de Pintores brasileiros (1986); Antologia de estética, teoria e crítica literária (1988); Antologia poética - Mário Quintana (1990); Antologia poética Lêdo Ivo (1990); Caderno de pintura (1991); Antologia poética - Gregório de Matos (1991); Antologia poética - Marcos Konder (1991); Antologia poética - Lila Ripol (1996); Dicionário de pintores brasileiros (1998).

Como é possível notar, Ayala exerceu um papel intenso de curador das artes plásticas, ao passo que contribuiu para a produção de história da literatura brasileira. Sobre este segundo ponto, inclusive, ele diz, em texto de apresentação da Antologia dos poetas brasileiros: fase modernista, a qual organizou em parceria com Manuel Bandeira, que a escrita de histórias da literatura é uma ótima forma de criar inimizades. Embora não tenha deixado o humor de lado, não é à toa que as antologias poéticas por ele organizadas foram todas sobre as obras de seus amigos (Lêdo Ivo, Lila Ripol, Marcos Konder). Também foi Ayala o responsável pelo tópico dedicado ao seu já citado amigo e "mentor intelectual" Lúcio Cardoso, na obra A literatura no Brasil - volume v, organizada por Afrânio Coutinho. O autor também possui dois textos publicados na revista Letras de hoje, da PUCRS: um sobre o poeta Zeferino Fagundes e o outro sobre a tradução de Martin Fierro.

Enquanto crítico, Ayala também leu diversos amigos e confidentes, chegando a comentar sobre estas críticas que publicaria, primeiramente, em cartas ao autor. Segue o exemplo de correspondência enviada à Clarice Lispector:

A CLARICE LISPECTOR Rio, 8/3/66. Clarice, aí vai mais uma nota sobre teu livro. Li-o vertiginosamente. Com pena de ti. Que mundo terrível o teu! Com pena de ti, sim. Porque acho que assumiste a grande tragédia do nosso tempo lítero-nacional. Única. Um livro como o teu não se escreve senão com sobre-humano sofrimento. Sinto que em cada clímax, e são duzentos mil os teus, consumas uma morte. Faz-me lembrar aqueles fascinantes golpes de morte dos filmes japoneses de samurai, um gesto, uma investida, um absoluto. Isto eu não disse no artigo mas vou registrar em meu diário. Assisto dolorido a tua descida ao inferno, eu pecador por quem pagas também. Gostaria de merecer as tuas milícias. Um abraço, Walmir Ayala. (HOBLICUA, 2018, p. 91)

Destacam-se em Ayala a astúcia e a generosidade de um leitor ávido, mas respeitoso. Confidente de grandes nomes da literatura nacional e curador de grandes centros artísticos ao redor do país, Ayala contribuiu como um embaixador das letras que estendeu sua paixão pela vida através de todos os gêneros artísticos. Pouco conhecido 
nos dias atuais, acredita-se que basta uma oportunidade para que leitoras e leitores encontrem em suas obras traços da genialidade sensível de um grande poeta, uma comovente interpretação dos percursos da vida em suas narrativas e a brilhante e desafiadora linguagem criativa de suas obras infanto-juvenis que, na verdade, servem para todas as idades.

Não é raro que a poesia seja considerada um gênero alienado em relação a temas sociais por leitores desavisados ou com pouca intimidade e leitura. Tirante uma espécie de preconceito com o gênero por parte de alguns, que podem pensar a poesia como um texto tão voltado para si mesmo que esquece do mundo do qual faz parte, o discurso lírico se revela, em última instância, diretamente vinculado às problemáticas históricosociais do sujeito escritor. Um bom exemplo disso é o trecho a seguir, parte de uma entrevista de Walmir Ayala presente na edição da Revista Hoblícua, citada anteriormente:

\begin{abstract}
ANDRÉ SEFFRIN: Falar em resistência, e a política na época? Você se envolveu?

WALMIR AYALA: Não participei da política dos anos 60 e 70 como ativista. Minha luta pessoal era muito grande para que eu pudesse me desviar. Defendi sempre a liberdade de expressão, tive minha casa invadida pelo DOPS, pronunciei um discurso famoso contra a censura ao receber um prêmio nacional de poesia em Brasília. Briguei publicamente com um general que censurava um livro de poetas novos coordenado por mim. Era minha forma de participar, sem provocar, mas defendendo os pontos moralmente básicos da dignidade de viver. Não ostento feridas nem prisões, porque Deus não quis. Nem me engajei nas causas radicais da esquerda e da direita. Tinha certeza de que tudo ia passar e sobreviveríamos, não apenas individualmente, mas como nação. Sim, sou otimista, acredito no futuro e num novo século de restauração dos valores mais altos. Um tempo de maior espiritualidade, de mais reflexão, de limpeza do lixo cultural que os conflitos de geração e de ideologia nos deixaram. Vejo a juventude desnorteada e aparentemente sem caminho, mas não posso deixar de acreditar que ela levará a chama adiante, para os que se preparam no silêncio, no mistério, na fatalidade histórica, para as novas e grandes construções.
\end{abstract}

Embora não tenha se considerado ativo nas questões políticas, a obra de Ayala sempre foi bem posicionada: ao tratar de temas como o sagrado e o profano, a fé, o sexo e a liberdade do amor, sua literatura sempre se mostrou polida, instigante e desafiadora. Não há espaço para o imóvel e o estável em suas narrativas, assim como seus versos se perfazem por sentimentos de angústia, busca pela paz e um amor caloroso e regenerativo. Através de sua arte, Ayala posicionou-se, sim, de maneira clara contra a opressão de gêneros e sexos, provocando uma exegese questionadora de planos 
linguísticos preocupados em expandir as possibilidades do cotidiano. A natureza de Ayala busca estabelecer relações calcadas na alteridade, evidenciando as tensões sociais entre classes sociais. O desprivilegio de alguns que, infelizmente, encontra do outro lado o privilégio excessivo de outros poucos é apresentado em obras como Estado de choque. Em Águas como espadas, a situação da modernidade das máquinas substituindo o valor dos indivíduos se revela de forma radical, apresentando poemas como "Tatuagem", no qual a marca intencional no corpo pode ser percebida como uma marca social e histórica de um coletivo que, aos poucos, esmaga as individualidades.

Como é possível observar, Ayala possui qualidades que o distinguem, desde o labor artístico-literário, com grande renome na área da literatura infanto-juvenil e da poesia, até sua preocupação em registrar na história os nomes das artistas e dos artistas que não apenas se consolidavam em seu tempo, mas também nomes que despontavam pelo Brasil na literatura e nas artes plásticas. Seu papel como crítico e historiador, em certa medida, é assinalado por grandes estudiosos da história da literatura, como Donaldo Schüler, e por veículos da mídia que assinalavam a crítica das artes, como o já citado A cigarra. No entanto, nos últimos anos, pouco se tem publicado a seu respeito. Por acreditar que essa situação pode mudar, esse estudo pretendeu fazer-se uma gota de chuva em meio a tantas possibilidades: não perdendo o otimismo, tão caro a Ayala, de que novas pessoas encontrem suas obras e por elas se vislumbrem.

Afinal de contas, a preocupação com o humano é um dos grandes motes para a escrita de Walmir Ayala. Influenciado por artistas como Clarice Lispector, Carlos Drummond de Andrade e Lúcio Cardoso, o autor salvaguarda seu otimismo mesmo frente a polarizações ideológicas tão fortes que surgem ao lado da violência do tempo da ditadura militar brasileira. O que aprendeu com seus mestres e amigos parece funcionar como uma lição de como seguir com a sua vida iluminada pela luz vibrante da infância e das crianças. Talvez por isso seja tão evidente seu apreço em produzir uma literatura de qualidade, que não se preocupe apenas em contar uma trama moralizante, mas que também desafie e instigue leitores de todas as idades a se encantar e a se apaixonar pela literatura. 


\section{Referências}

AYALA, Walmir. Diário I — Difícil é o reino. Rio de Janeiro: GRD, 1962.

CARNEIRO, Alan Silvio Ribeiro. Uma carta de Hilda Hilst a um jovem poeta brasileiro. Contexto, Espírito Santo, nº 18, 2010.

CASTELLO, José. Prosa e Verso. O Globo. 30 de julho de 2011. Disponível em: < http://lemetro.ifcs.ufrj.br/resenha_nas_trilhas_da_amazonia.pdf> Acesso em 28.08.2018.

DAMASCENO, Beatriz. Anotações, relances, colagens, inventários: os diários inéditos de Walmir Ayala in.: Arquivos pessoais e cultura: uma abordagem interdisciplinar. Org.: OLIVEIRA, Lucia Maria Velloso; VASCONCELOS, Eliane. Rio de Janeiro: Fundação Casa Rui Barbosa, 2015.

HOBLICUA. Especial Walmir Ayala. Maquiné: № 5, 2018.

HOHLFELDT, Antônio. Esta sondagem cruel e autêntica. Correio do povo. Porto Alegre, 7 de abril de 1973.

LUCCHESI, Marco. Melhores poemas: Walmir Ayala. São Paulo: Global, 2008.

MOREIRA, Daniel da Silva. A fundação de uma escrita autobiográfica dissidente: os diários de Lúcio Cardoso, Walmir Ayala e Harry Laus e a tematização da homossexualidade. Litterata, Ilhéus, vol 8.1, p. 42-62, 2018.

SCHÜLER, Donaldo. A poesia no Rio Grande do Sul. Porto Alegre: Mercado Aberto, 1987.

WALMIR AYALA. Autores gaúchos. No 22. Porto Alegre: Instituto Estadual do Livro, 1989.

WALMIR AYALA: mais poesia. A Cigarra. Ano 52, no9, setembro de 1966.

Disponível em: <

http://200.144.6.120/uploads/acervo/periodicos/jornais/CI19660909.pdf> Acesso em 01.09.2018. 
${ }^{1}$ Agência de fomento: "O presente trabalho foi realizado com apoio da Coordenação de Aperfeiçoamento de Pessoal de Nível Superior - Brasil (CAPES) - Código de Financiamento 001 